\title{
Piloleiomyoma with segmental distribution - Case report*
}

\author{
Melina Maria de Sousa Albuquerque ${ }^{1}$ \\ Igor Santos Costa ${ }^{2,3}$ \\ Francisco José Dias Branco ${ }^{1}$
}

\author{
Camila Farias Rocha ${ }^{1}$ \\ Rodger da Rocha Maia ${ }^{1}$ \\ Heitor de Sá Gonçalves ${ }^{1}$
}

DOI: http:/ / dx.doi.org/10.1590/abd1806-4841.20153769

\begin{abstract}
A bstract: Piloleiomyoma is an uncommon benign neoplasm arising from the erector pilorum muscle. It presents as reddish-brown papules or nodules, in general located on the limbs or trunk, often painful. The present paper describes a case of piloleiomyoma with segmental distribution on left trunk, with an important expression of pain. Keywords: Dermis; Leiomyoma; Skin; Skin neoplasms
\end{abstract}

\section{INTRODUCTION}

Leiomyomas are benign skin tumors that arise from smooth muscle. According to its origin, it can be classified as piloleiomyomas, vascular leiomyomas and genital leiomyomas, emerging from arrector pili muscle, dermal blood vessels and genitals, respectively. Cutaneous leiomyomas are responsible for $75 \%$ of extrauterine leiomyomas. ${ }^{1-3}$

The piloleiomyoma is a benign skin tumor that originates from smooth muscles of the arrector pili muscle, described by Virchow in 1854 . Epidemiologically, it is more common between the second and fourth decades of life and it can affect both sexes. Clinically, it presents as dermal papules or nodules, varying from skin-colored to reddish-brown lesions, which may be multiple or solitary. In general, it affects the extremities, followed by trunk, face and neck. ${ }^{2,3}$ It is often associated with spontaneous or induced pain, especially by cold, winter or friction. ${ }^{1,4}$

\section{CASEREPORT}

Male patient, 37 years old, industrialist, with history of beginning of lesions in the left side of back for about 11 years, with gradual increase in quantity associated with significant local pain, mainly related to the cold. On examination, there were grouped intradermal papules and nodules, skin-colored and reddish-brown, fixed to the skin, but not to deeper tissues, with segmental distribution on the back (Figure 1). Patient presented some painful lesions on palpation. He denied local or systemic diseases.

Histopathological examination revealed mesenchymal spindle-cell neoplasm located in the dermis, composed of elongated cells of eosinophilic

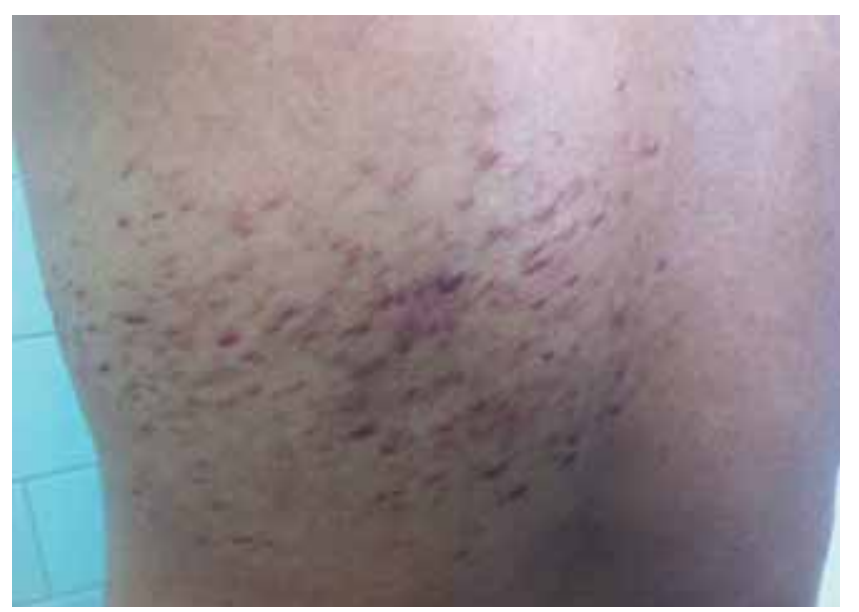

FIGURE 1: Close-up view of grouped intradermal papules and nodules, skin-colored and reddish-brown, fixed to the skin, with segmental distribution on the back 
cytoplasm and ill-defined boundaries, spindle-shaped nucleus and blunt edges, forming multiple cell bundles with well-defined boundaries. Examination showed no nuclear atypia (Figures 2 and 3). Diagnosis was also confirmed by Masson trichrome staining (Figure 4).

\section{DISAUSSON}

Cutaneous leiomyomas are uncommon neoplasms and the present case reports a rare distribution of piloleiomyoma: with a segmental aspect. In the literature, few cases have been reported with this distribution. ${ }^{1,2,4-7}$ The precise etiology of piloleiomyoma remains unknown to this date, but genetic alterations are probably involved due to the

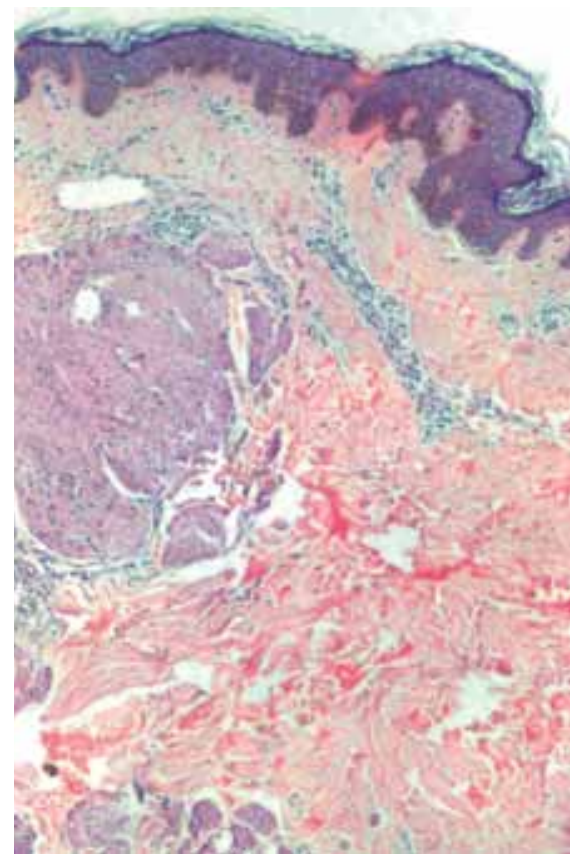

FIGURE 2: The

photo shows mesenchymal spindle-cell neoplasm located in the dermis, composed of elongated cells of eosinophilic cytoplasm and ill-defined boundaries, spindle-shaped nucleus and blunt edges, forming multiple cell bundles with well-defined boundaries. (HE,40x)

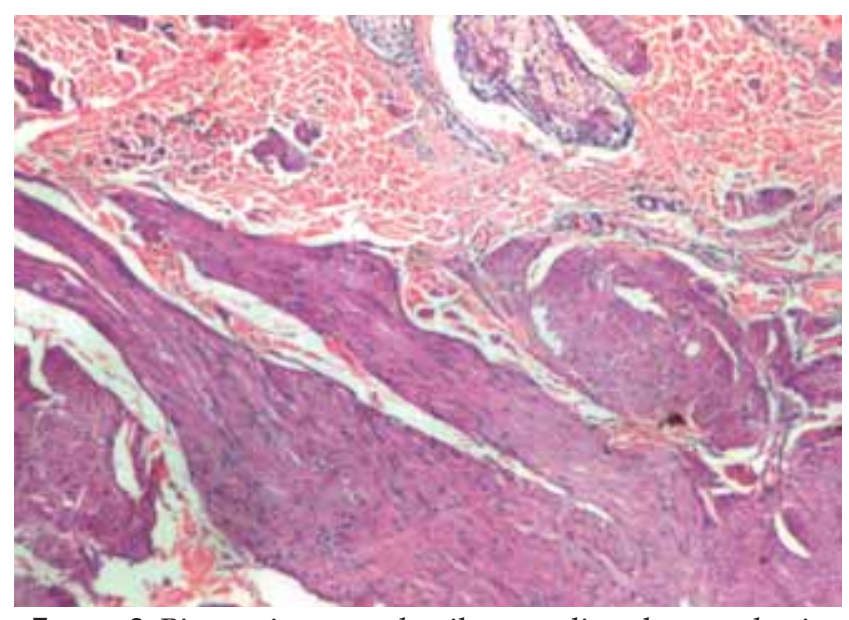

FIGURE 3: Biggest increase details, revealing the neoplastic cells with fusiform nuclei and blunt edges. Note that there is no nuclear atypia. (HE, 100x).

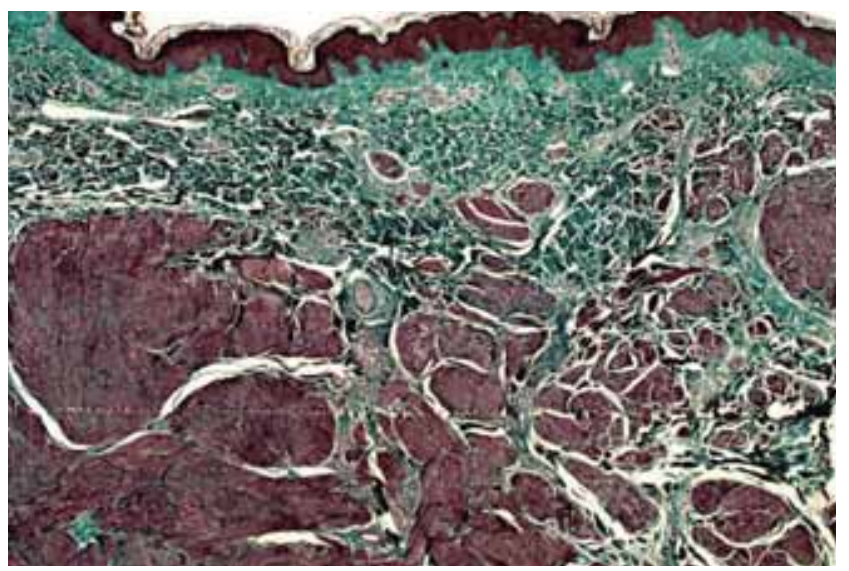

Figure 4: Photo with Masson's Trichrome (HE,100x): The special coloring allows to observe a good distinction of the neoplasia in red, compared to collagen bundles of dermis in green. Again, it is noted the characteristic of the tumor to form various neoplastic sets in the dermis

occurrence of familial cases, with report of autosomal dominant inheritance for multiple piloleiomyomas. ${ }^{6,7}$ Pain, frequent symptom of this condition, is believed to be caused by cutaneous nerve compression, injury or by the contraction of muscle fibers of the tumor. ${ }^{1}$

Differential diagnoses are: dermatofibromas, Schwannomas, neurofibromas, angiolipomas, nevus, lipomas, eccrine spiradenoma, metastases and angioleiomyoma. ${ }^{2-4}$ The latter, with clinical and histopathological characteristics very similar to those of piloleiomyoma, differs clinically to be generally a solitary lesion in the lower limbs and to present, histopathologically, many tortuous blood vessels, some of them thick-walled, among smooth muscle bundles of the tumor. This intimate connection of muscle bundles with the vessel makes it difficult to distinguish between the vascular wall and smooth muscle cells of the tumor.

Treatment of piloleiomyoma can be based on patient symptoms. Often, camouflaging the area and avoiding exposure to cold and trauma are sufficient. Removal of painful or unaesthetic lesions, when small in number, is a good option. ${ }^{3}$ For the most extensive and symptomatic cases, although success in clinical management is not always reached, there are other options: calciumchannel blockers (CCB), which blocks the calcium inflow to the smooth muscle, such as nifedipine; alpha-adrenergic blocking agents, such as phenoxybenzamine and doxazosin; and gabapentin, which has been a good therapeutic option, with fewer adverse events. ${ }^{8,9} \mathrm{CO} 2$ laser is also described as an alternative; but cryotherapy and electrocoagulation have been proven to be ineffective. ${ }^{10}$ Recurrences are frequent, particularly in patients with multiple lesions. However, no one knows for sure whether they are new lesions or if they result from the growth of partially excised lesions. ${ }^{1} \square$ 


\section{REFERENCES}

1. Parreira LM, Sípoli JM, Mercante AM, Orfali RL, Levites J. Case for diagnosis: (unilateral multiple piloleiomyoma). An Bras Dermatol. 2009;84:197-9.

2. Malhotra P, Walia H, Singh A, Ramesh V. Leiomyoma cutis: a clinicopathological series of 37 cases. Indian J Dermatol. 2010;55:337-41.

3. Kudur MH. A generalized multiple cutaneous piloleiomyomatosis in a young male: Rare case report. Indian J Dermatol. 2013;58:245.

4. Arfan-ul-Bari. Zosteriform cutaneous leiomyoma: a rare cutaneous neoplasm. J Coll Physicians Surg Pak. 2013;23:586-7.

5. Kitoh A, Akiyama H, Yoshida Y, Tanaka T. Multiple piloleiomyomas: do they follow dermatomes or blaschko lines? J Dermatol. 2003:30:851-2.

6. Smith CG, Glaser DA, Leonardi C. Zosteriform multiple leiomyomas. J Am Acad Dermatol. 1998:38:272-3.

7. Sada A, Misago N, Inoue T, Narisawa Y. Segmental multiple cutaneous piloleiomyoma with an overlying epidermal proliferation. J Dermatol. 2007:34:665-7.

8. Chaves AJ, Fernández-Recio JM, de Argila D, Rodríguez-Nevado I, Catalina M. Zosteriform Cutaneous Leiomyoma. Satisfactory Treatment With Oral Doxazosin. Actas Dermosifiliogr. 2007;98:494-6.

9. Alam M, Rabinowitz AD, Engler DE. Gabapentin treatment of multiple piloleiomyoma-related pain. J Am Acad Dermatol. 2002;46:S27-9.

10. Christenson LJ, Smith K, Arpey CJ. Treatment of multiple cutaneous leiomyomas with C02 laser ablation. Dermatol Surg. 2000;26:319-22.

\author{
M AILING ADDRESS: \\ $M$ elina $M$ aria de Sousa A I buquerque \\ 1033, Pedro I Street, \\ Downtown \\ 60035-101 Fortaleza - CE. \\ Email: melinaalb@hotmail.com
}

H ow to citethis article: Albuquerque MMS, Rocha CF, Costa IS, Maia RR, Branco FJD, Gonçalves HS. Piloleiomyoma with segmental distribution: a case report. An Bras Dermatol. 2015;90(3 Suppl 1):S178-80. 